\title{
El proyecto arguediano de construir una lengua literaria nacional
}

\author{
Dorian EsPezúa SALMÓN \\ Universidad Nacional Mayor de San Marcos \\ doriansolee@gmail.com
}

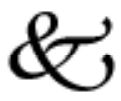

Resumen

\begin{abstract}
En un país plurilinguie y multicultural como el Perú, la lengua en la que se expresa la literatura es un problema ético. José María Arguedas se propuso representar los principales conflictos sociolingüísticos de la realidad peruana en su literatura y para ello llevó a cabo una pelea verdaderamente infernal con la lengua. Esta pelea dio como resultado la creación del lenguaje literario peruano, de la lengua "misturada", del quechuañol, lo que evidencia el gran aporte técnico del novelista peruano.
\end{abstract}

Palabras claves: Arguedas, lengua, bilinguiismo, quechuañol, mistura, sesquilinguiísmo, traducción.

\begin{abstract}
Abtsract
In a multilingual and multicultural country like Peru, the language which expresses the literature is an ethical problem. José María Arguedas is proposed to represent the major conflicts of the sociolinguistic situation in Peru in their literature and it held a truly hellish fight with his language. This fight resulted in the creation of the Peruvian literary language, the language "mixed" from quechuañol, which shows the great Peruvian novelist technical input.
\end{abstract}

Keywords: Arguedas, Language, Bilingualism, Quechuañol, Sesquilinguiísmo, Translation.

\section{Tipos de mestizajes}

Antonio Melis dice con mucha razón que "la reflexión sobre el problema de la lengua acompaña de manera apremiante todo el itinerario de José María Arguedas” (2011: 279). En efecto, el problema de la lengua o más precisa- 
mente de la expresión escrita en Arguedas ha dado como fruto una enorme producción bibliográfica que, en líneas generales, sostiene que los conflictos culturales y linguiísticos del escritor se ven reflejados en su escritura. Frente a la idea de una supuesta vacilación, desarticulación, incoherencia, ambiguiedad o debilitamiento respecto del proyecto arguediano de construir un lenguaje literario llamado "mistura" para expresar el multilingüismo y la pluriculturalidad del Perú, sostengo que más bien estamos frente a un proyecto coherente que, en sus diferentes estadios, calza perfectamente con los referentes representados y con su apuesta por el mestizaje y la integración de las culturas y lenguas peruanas. Como dice Alberto Escobar, Arguedas "traspone a la escritura las tensiones del contexto sociocultural del universo andino" (1984: 20). Esto supone asumir conflictos y contradicciones que son propios de una sociedad multilinguie, de un sujeto bilinguie y bicultural y, específicamente, de una literatura bilinguie ${ }^{1}$. En consecuencia, el lenguaje literario de Arguedas tiene diferentes manifestaciones que, sin embargo, forman parte del mismo proyecto que consiste en construir un lenguaje literario que, por un lado, (re)presente los conflictos linguiísticos que forman parte de los conflictos socioculturales y, por otro lado, evidencie los procesos de integración o mestizaje².

\section{Mestizajes y no purezas}

Que Arguedas sea un firme defensor de las culturas indígenas es una verdad incuestionable, pero de ahí a afirmar sectariamente que Arguedas defiende sólo la cultura y la lengua indígena sin considerar su apuesta por la integración, el sincretismo, la transculturación o el "mestizaje cultural" convierte la primera afirmación, por lo menos, en incompleta. Con la claridad que lo caracteriza, Alberto Escobar (1984. 51) afirma que los personajes principales en la narrativa arguediana son social y culturalmente mestizos porque representan

1 Kathlee March en su artículo "El bilingüismo literario y la verosimilitud" (1984) sostiene que hay dos tipos de bilingüismo en la literatura latinoamericana. Uno, que podría denominarse coordinado, donde se alternan y combinan dos idiomas. Este sería el caso de la literatura puertorriqueña donde se "alternan" y "combinan" el inglés y el español. Esta literatura además tiene un público lector que puede consume libros marcadamente bilingües. El otro tipo de bilingüismo, que podríamos llamar subordinado, se encuentra más condicionado por las limitaciones y prejuicios linguísticos del público consumidor. Este es el caso de la literatura que se produce en la zona andina donde el bilingüismo varía en cantidad y calidad por ejemplo cuando se muestra el contacto quechua-castellano.

2 Carlos Huamán en su libro Pachachaka. Puente sobre el mundo: narrativa, memoria y símbolo en la obra de José María Arguedas (2004) prefiere hablar de "proceso de transcreación" entendido como el proceso de creación de una lengua original que traduzca la lengua y cultura quechua al castellano en la medida de lo posible conservando el sentido poético y la carga emotiva del quechua. 
una sociedad inmersa en importantes procesos de movilidad social. No se puede sostener que en Arguedas primero y prioritariamente hay una preocupación por lo indígena y luego, de un modo complementario, por lo mestizo. Es más bien evidente que su interés por indios y mestizos se da al mismo tiempo. Tampoco se puede sostener que en Arguedas hay un interés sólo por los conflictos socioculturales de la sierra cuando en toda su narrativa se muestra lo que Antonio Cornejo Polar (1995) ha llamado la "gesta del migrante" que permite la articulación de elementos provenientes de otras localidades. Arguedas estaba convencido de que el mestizo representaba a la mayoría de los peruanos y de que "es rarísimo, si no imposible en el Perú encontrar alguna manifestación cultural que haya permanecido pura, ya sea de la hispánica o de la india" (1957: 103). Parafraseando a Arguedas, es inexacto considerar que la cultura permanece intangible y que lo peruano está representado sólo por lo indio. Arguedas tiene claro que las culturas europeas e indias han convivido y se han influenciado mutuamente de manera que se ha dado origen al mestizo hablando en términos culturales y no sólo en términos de raza. Arguedas dice: "Quienquiera puede ver en el Perú indios de raza blanca y sujetos de piel cobriza, occidentales por su conducta" (Escobar, 1984: 52 y Arguedas, 1975: 2). Ya los estudios sobre la narrativa arguediana han evidenciado el complejo mundo sociocultural de sus novelas donde se distinguen tipos de indios, tipos de mestizos o cholos, tipos de migrantes, tipos de terratenientes o hacendados y tipos de "señores".

El tema del mestizaje cultural en los escritos antropológicos de Arguedas ha sido sesudamente investigado recientemente por Renatto Merino Solari (2011) quien ha evidenciado la opción arguediana por un mestizaje que se reelabora permanentemente, los diversos tipos de mestizaje directamente relacionados con factores histórico-socio-culturales y la superación del indigenismo tradicional. Merino nos recuerda que el mestizaje flexible del que habla Arguedas implica el mantenimiento de un "ethos comunitario" que marca al individuo andino de modo que hace muy difícil destruir su cultura o su "personalidad básica”. El propio Arguedas, nos recuerda Merino, se definía como un "individuo quechua moderno". En tal sentido el problema no es el cambio cultural, que puede ser negativo o positivo, sino los modos en que esos cambios afectan la matriz cultural andina.

Arguedas, siguiendo a Jorge Basadre -quien sostenía la necesaria defensa del mestizaje- aseveraba, por un lado, que había aparecido un personaje, poco estudiado, debatido y comprendido que era el mestizo entendido como un "producto humano" que estaba desplegando una actividad cada vez más importante en el mundo andino y, por otro lado, que el indio se estaba diluyendo por causas diversas ente las cuales tal vez las más importantes sean la migra- 
ción, la castellanización, la evangelización y la modernización de la sociedad peruana. Las referencias a los indios y mestizos en los escritos de José María Arguedas son abundantes al punto que se puede decir que ambos personajes se mezclan y hasta confunden.

Veamos algunas citas sacadas de su texto "Canto kechwa. Con un ensayo sobre la capacidad de creación artística del pueblo indio y mestizo" (2004 [1938]): "La mayoría del pueblo racialmente mestizo se mantiene indio, en costumbres y por su condición social; su vida es indígena en todas sus manifestaciones, y a todos se les denomina indios" (2004 [1938]: 94). ¿Acaso estos no son los "indígenas mestizos" de los que habla Marisol de la Cadena (2004)? ¿No hay acaso varias formas de ser indio y varias formas de ser mestizo? "Los mestizos propiamente dichos -medio mistis, taksa k'alas, chalos - constituyen en la sierra del Perú un estado social superior al del indio, aunque no en todos los casos su condición económica sea mejor. La expresión artística del mestizo es de la más pura ascendencia indígena” (2004 [1938]: 94). Esto quiere decir que hay diferentes clases, tipos o grados de mestizaje. Algunos más cercanos a lo indio y otros más pegados a lo hispano. "El arte popular mestizo es de la más neta ascendencia indígena: en lo que se refiere a las canciones, por ejemplo, los mestizos cantan como suyos los waynos indígenas, salvo aquellos que son lo más puro de folklore indígena" (2004 [1938]: 94). Arguedas nos presenta un mestizaje serrano influenciado fuertemente por la cultura indígena. En este mismo sentido y en el mismo texto dice: "En el pueblo mestizo tiene mucho mayor dominio el elemento indio. Es que, además de la influencia racial y del ambiente, en las relaciones de la vida diaria, de la vida en todos sus aspectos, el mestizo está mucho más cerca del indio" (2004 [1938]: 95). Según esta cita el mestizo está determinado por la "raza" india y el ambiente en el que vive el indio de manera que es el componente indígena la matriz cultural (Gruzinski: 2000) predominante en el mestizo.

No hay que olvidar que para Arguedas el mundo andino era ya el resultado de siglos de intercambio cultural. Esto se puede evidenciar, por ejemplo, en su texto "El charango" (1989 [1940]). Tampoco hay que olvidar que Arguedas vio en los procesos de migración la formación de la nueva sociedad peruana. Su preocupación por la integración cultural se puede encontrar en textos como "El Perú y las barriadas" (2004 [1961]), "El indigenismo en el Perú" (1989 [1965]) o "A nuestro padre creados Túpac Amaru (Himno Canción) (2004: [1966]). ¿Por qué era importante para Arguedas la integración? ¿Cuál era la razón de ser del proceso de "misturización”? La siguiente cita de Alberto Escobar es esclarecedora en varios aspectos porque evidencia la integración de las prácticas culturales andinas y amazónicas en lo que he denominado la cultura "chicha" (Espezúa: 2008). Desde la perspectiva de Escobar, a quien citamos a continua- 
ción, la integración es el mejor método de conservación de nuestro patrimonio cultural que incluye a nuestro patrimonio linguíístico:

Cuando se habla de "integración" en el Perú se piensa invariablemente en una especie de aculturación del indio tradicional a la cultura occidental; del mismo modo que cuando se habla de alfabetización no se piensa en otra cosa que en la castellanización. Algunos antropólogos [...] concebimos la integración en otros términos o dirección. La consideramos no como una ineludible y hasta inevitable y necesaria aculturación, sino como un proceso en el cual ha de ser posible la conservación o intervención triunfante de algunos de los rasgos característicos no ya de la tradición incaica, muy lejana, sino de la viviente hispano-quechua que conservó muchos rasgos de la incaica. Así creemos en la pervivencia de las formas comunitarias de trabajo y vinculación social que se han puesto en práctica $[\ldots]$ entre las grandes masas no sólo de origen andino sino muy heterogéneas de las "barriadas", que han participado y participan con entusiasmo en prácticas comunitarias que constituían formas exclusivas de la comunidad indígena. (1984: 61-62)

Arguedas no definía lo indio desde una posición purista como se deduce de la cita anterior. No se refería al indio situado en el tiempo de los Incas o congelado en el periodo colonial, sino más bien al indio hispano-quechua viviente en la actualidad. Lo indio era también para él un producto del contacto cultural que, por lo tanto, había pasado por procesos de transculturación. Veamos otro texto de Arguedas que apunta en ese sentido:

Al hablar de la supervivencia de la cultura antigua del Perú nos referimos a la existencia actual de una cultura denominada india que se ha mantenido, a través de los siglos, diferenciada de la occidental. Esta cultura, a la que llamamos india porque no existe ningún otro término que la nombre con la misma claridad es el resultado del largo proceso de evolución y cambio que ha sufrido la antigua cultura peruana desde el tiempo en que recibió el impacto de la invasión española. (2004 [1952]: 185)

Tenemos entonces una primera conclusión. La lengua escrita en la que debe hacer hablar a los personajes indios y mestizos de sus novelas no es ni el "castellano puro", ni el "quechua puro", ni un tercer idioma "creado". No podrían serlo puesto que tanto el quechua como el castellano han asimilado préstamos linguiísticos. La lengua en la que debía hacer hablar de modo verosímil a los indios y mestizos era un "mistura" de castellano y quechua porque esa "mistura" existía en los hablantes indios y mestizos del mundo andino. El problema para Arguedas consistía en cómo hacer inteligible el bilinguiismo quechua-castellano de ese entonces a un público lector acostumbrado a que los indios se expresen en castellano o en un "remedo" de castellano andino o de lengua nativa. No hay que olvidar que el quechua que aprendió a hablar Arguedas y en el que tam- 
bién escribió es un idioma contaminado o mezclado con hispanismos. Su tarea entonces consistía, por un lado, en crear casi un tercer idioma, (Rowe, 1979: 60-61) o en crear "una lengua 'artificial', o sea 'literaria', que quiere expresar la situación de desgarramiento linguístico de un mundo dividido" (Melis, 2011: 377), y, por otro lado, en mostrar el conflicto del bilingüie mestizo o indio.

\section{Lengua del autor, lengua del narrador y lengua de los personajes}

Una segunda cuestión ineludible es la diferenciación que hay que hacer entre la lengua del autor, la lengua del narrador y la lengua de los personajes. En este punto también sigo el imprescindible trabajo de Alberto Escobar (1984) quien diferenciaba el habla coloquial de José María Arguedas, la lengua del escritor de ensayos no literarios y la lengua del novelista enfrentado al problema de recrear y hacer entendible a los lectores las lenguas y los dialectos del Perú expresados por sus personajes.

Se trata, nos guste o no, de algo que acontece en el "artificio" de la lengua escrita con la intención de ser leído como producción artística, esto es, de discurso literario. El término artificio puede parecer violento, pero se comprende mejor en su recto alcance cuando pensamos en el lenguaje de los relatos que simulan reproducir la conversación y los giros del habla coloquial. (1984:66)

Los ejemplos de Alberto Escobar (1984) cuando analiza las sucesivas versiones de Agua $(1935,1954,1967)$ demuestran que la lengua "artificial" arguediana no hace sino reflejar fenómenos linguí́sticos reales ${ }^{3}$. Antonio Cornejo Polar habla de un realismo linguístico que debe revelar la realidad y "ser fiel a la norma linguíística propia del mundo que se representa literalmente" (1970: 29). Pero este realismo linguiístico no se queda sólo en la copia de una norma efectivamente hablada, sino que crea una lengua nueva -el quechuañol- que refleja y revela el mundo de la heterogénea sociedad peruana. Para Cornejo: "El esfuerzo linguiístico de Arguedas tiene, pues, una dirección muy precisa:

3 Cito a Alberto Escobar quien en su libro Arguedas o la utopía de la lengua (1984) dice: "Planteadas así las cosas, se hace más comprensible hasta qué grado son meros repertorios inexpresivos las listas que podríamos organizar de modo muy general: ciertas voces de origen quechua, ciertas listas de sufijos, falta de empleo de los artículos, desajustes en la concordancia, profusión de oraciones coordinadas, frecuentes construcciones en gerundio; traslado del verbo a final de emisión, pérdida de la forma pronominal del pronombre personal en ciertas posiciones, abundancia del diminutivo, uso extendido incluso a formas que no lo aceptan regularmente, como adverbios y gerundios, y etc., etc., además de las transcripciones casi fonéticas que confunden $e$ con $i$ y $o$ con $u$, o la alternancia de los pronombres personales de segunda persona en el registro de formalidad, etc., etc. Repetimos que este inventario constituye un fondo o repositorio de apariciones anotadas en tal o cual pasaje de tal libro, pero ellas en sí dicen muy poco acerca de la obra, si se les toma aisladamente" (89). 
ceñir la palabra a su referente, hacerla transparente e instrumental, permitir que sea como una ventana abierta sobre la realidad" (1970: 29). En la misma línea de Antonio Cornejo Polar está Ricardo González Vigil para quien: "El realismo de Arguedas se apoya, precisamente, en esa confianza en el lenguaje como expresión de la realidad, o sea, un realismo lingüístico" (2002: 54). Obviamente este realismo linguiístico debe hacer más inteligible lo andino para personas de otras latitudes.

Otra es la opinión de Jana Hermuthová quien sostiene que Arguedas: "Se esfuerza en construir paso a paso un lenguaje ficticio que en realidad nadie usa en el área andina" (2004: 43). Pero esta afirmación se relativiza si tomamos en cuenta una opinión anterior donde Hermuthová escribe que para Arguedas "lo esencial es contar el mundo quechua con veracidad y desde su profundidad, descubre finalmente la única manera de hacerlo: ceñir la palabra al objeto denominado lo más posible para que la palabra represente una ventana transparente cuyos cristales dejen ver la realidad" (2004: 42). Por su parte Roland Forgues ha dicho que en la narrativa arguediana hay un realismo literario al mismo tiempo que una exigencia por la verdad y la inteligibilidad. Este realismo de la escritura arguedina, según Forgues, se nutre también del mito y la historia de modo que: "Las palabras quedan investidas de un poder mágico cuya virtud primera es, como lo hemos dicho antes, volver a encontrar la esencia misma de los seres y de las cosas" (1989: 63). En efecto, la (re)creación de la lengua de los personajes implica su basamento en las variaciones sociolingüísticas del castellano y quechua que se hablan en situaciones comunicativas reales porque de alguna manera (re)crear es modificar, adaptar, acomodar, ajustar, arreglar lo que previamente se conoce. Subrayo esto porque es frecuente que se cometa el error de considerar que la lengua de los personajes arguedianos es la lengua del narrador o es la lengua del autor. Parafraseando a Alberto Escobar diremos que la maestría de Arguedas por construir una lengua literaria, basada en los conflictos sociolinguísticos de los habitantes de los Andes, se aprecia en la sintaxis narrativa que muestra, "en la misma superficie, una valencia linguiística doble, de dos lenguas diversas, no de simples variedades dialectales o sociales o de registros distintos" (1984:72). Escobar, en la siguiente cita, explica que el "dilema" se resuelve en la ficción donde se "recrea" una lengua en la que el lector asume que el indio se está expresando en quechua:

Esta mecánica supone dos cuestiones: a. el lector sabe que él no domina ni conoce el quechua; y b. sabe así mismo que el lector indio no tiene control suficiente del castellano y que aparece como si estuviera hablando en quechua. De esta manera la relación translinguiística actualiza el mensaje quechua, hace presente lo que no está a la vista; hay una correlación entre los dos términos de la ecuación: el castellano es lo 
presente y el quechua la lengua copresente, merced a la organización de los rasgos de la literaridad arguediana. (1984: 72)

La lengua de José María Arguedas se hace evidente en los textos de no ficción que pronunció y escribió. Una muestra palpable es su intervencióntestimonio en el primer encuentro de narradores peruanos que se realizó en Arequipa en 1965 donde el escritor peruano evidencia un castellano andino estándar perfectamente comprensible por cualquier hispanohablante. También podemos notar su alta competencia en castellano (no hay que olvidar que era profesor de castellano) en sus artículos, ensayos, cartas o en los diarios de $E l$ zorro de arriba y el zorro de abajo si es que queremos considerar a estos como escritura autobiográfica. Claro que a esto hay que sumarle su competencia en el quechua que se manifiesta en la escritura de cuentos y poemas, en la recopilación de la tradición oral y en sus trabajos de "traducción". Arguedas decía: "Yo no soy un aculturado; yo soy un peruano que orgullosamente como un demonio feliz habla en cristiano y en indio, en español y en quechua". (2009 [1968]) De modo que podemos afirmar que Arguedas era un escritor bilingüe coordinado que podía desenvolverse muy bien y de manera competente en ambas lenguas y también evidenciar la copresencia de las mismas en su castellano andino ${ }^{4}$. En tal sentido, no comparto la opinión de Estelle Tarica (2006) que, apoyada en los planteamientos del escritor martinicano Eduoard Glissant, sugiere que Arguedas tenía dificultades para expresar en una lengua algo imposible de expresar en otra. Más bien creo, y esto se refiere a la lengua que Arguedas elabora, que la maestría de Arguedas está en hacernos sentir el quechua en el castellano y viceversa. La diferenciación de escrituras o registros ha sido evidenciada también por Nelson Osorio Tejeda a quien cito a continuación:

Creemos que la escritura de Arguedas se despliega en tres dimensiones del lenguaje. Para mostrar y exponer el mundo indígena y mestizo del Perú, crea en sus palabras- un lenguaje especial, un lenguaje literario inventado, mestizo y transculturado, tal vez su aporte más llamativo y singular, sobre todo para el interés de los estudiosos de su obra. Pero para dar salida a sentimientos y pasiones más hondas, se expresa en quechua, su lengua materna. Y por último, para sus textos reflexivos (de carácter antropológico, o de opinión sobre asun-

4 Roland Forgues en "El mito del monolingüismo quechua de Arguedas" (1991) ha lanzado la hipótesis de Arguedas era, hasta los 7 u 8 años aproximadamente, monolinguie castellano. Para efectos de este trabajo no es relevante discutir si Arguedas fue primero monolingüe quechua o monolingüe castellano. Lo que nos interesa es que el escritor reconoce al quechua como su primera lengua de modo que, más bien, asumimos su temprano bilingüismo. Al respecto se puede revisar el capítulo III titulado "Rimaypi nina. Fuego en la palabra (el lenguaje en el universo narrativo arguediano)" (2004: 89-115) perteneciente al libro Pachachaka. Puente sobre el mundo: narrativa, memoria y símbolo en la obra de José María Arguedas (2004) donde Carlos Huamán hace evidente las contradicciones en la argumentación de Roland Forgues. 
tos sociales o políticos), emplea el castellano normalizado y formal, validado intencionalmente (2010: 416).

Siendo importante un estudio de la lengua del autor creo que es más significativo el estudio de lo que a Arguedas le preocupaba, esto es, el cómo debía hacer hablar a sus personajes. Arguedas era un convencido de que los indios debían hablar en su lengua de modo tal que nadie usurpe ni desfigure su voz, pero era consciente también de las limitaciones en términos de público lector. Hay que tener en cuenta que Arguedas muestra una complejidad cada vez mayor en sus mundos representados. Tomás Escajadillo y Antonio Cornejo Polar, siguiendo lo declarado por el propio Arguedas, han estudiado bien la ampliación de los mundos representados o de los universos narrativos arguedianos. Esto implica también la ampliación de los lenguajes representados. En consecuencia, difiero de lo planteado por Estelle Tarica (2006) quien sostiene que Arguedas, en Los ríos profundos, renunció a la mistura, expresada en los cuentos de Agua o en Yawar fiesta, para pasar a una poética de la "traducción"5. Para Tarica estamos frente a una ambivalencia puesto que, por un lado, Arguedas tiene plena confianza en lo que su lenguaje, que es el lenguaje de esta tierra caracterizado por su decir fuerte y limpio, dice y, por otro lado, "confiesa haberse equivocado a la vez que defiende su error" (2006: 23]. Es posible sostener que Arguedas "abandonó" su proyecto linguíístico a favor de una prosa castellana más comprensible aunque yo usaría el verbo "reformuló". Pero, creo que no hay elementos suficientes para sostener que su lenguaje misturado haya fracasado rotundamente y tampoco creo que haya suficientes datos para argumentar que: "Ya para 1950, buscaba definitivamente arrancar el quechua del castellano" (2006: 36). El estudio del proyecto linguiístico arguediano también debe incluir su poesía y no sólo su narrativa. Considerando lo anterior, el proceso no va de la mistura a la castellanización o de la mistura a la "traducción”. Primero porque Arguedas es un "traductor" desde Canto Kechwa (1938). Al respecto, Nelson Osorio sostiene, con mucha razón, que Arguedas no hace traducciones sino "versiones poéticas" de las canciones y cantos quechuas

5 Tal vez la opinión de Estelle Tarica esté influenciada por el punto de vista de William Rowe a quién cito a continuación: "Antes de escribir Los ríos profundos, Arguedas trató de crear lo que era casi un tercer idioma "ni quechua ni castellano- sino algo que combinase ambos. Sin embargo, cuando comenzó a escribir Los ríos profundos ya había llegado a la conclusión de que era imposible establecer una vía media entre ambos idiomas" (1979: 60-61). A su vez, la opinión de Rowe, está sustentada en el texto de Arguedas "La novela y el problema de la expresión literaria en el Perú" (2009 [1950]) donde Arguedas declara su voto a favor del castellano y dice que con Los ríos profundos el proceso de creación de una lengua "misturada" ha concluido. Sin embargo, a pesar de lo que diga el propio Arguedas (me refiero a su práctica escritural consciente), creo que su escritura en los textos posteriores a Los ríos profundos demuestra que el conflicto expresivo sigue latente. 
(2010: 412) y Antonio Melis (2011: 335) habla de una "doble redacción" que no es lo mismo que una (auto)traducción. Segundo, porque cuando Arguedas escribe en castellano, deja traslucir la fonética, morfología y sintaxis quechua. Tercero, porque termina escribiendo en un quechua misturado, democratizado, en una suerte de Koiné (Melis, 2011: 271), los poemas de Katatay (1972). Así planteadas las cosas, el lenguaje "misturado" tiene diferentes manifestaciones que corresponden con los diferentes niveles de ampliación de los universos literarios arguedianos. Veamos el proceso.

\section{Proceso de construcción de la lengua arguediana}

Hay que dejar en claro que no estamos frente a un proceso lineal aunque lo expliquemos de ese modo, estamos frente a un proceso complejo en términos de propuestas que muchas veces evidencian las marchas y contramarchas en la propuesta arguediana. Cito a Antonio Melis para apoyar mi idea:

La contradicción, que es el alimento de su búsqueda incesante, no se manifiesta solamente en una visión cronológica de sus escritos sobre la lengua. Dentro de una misma época y hasta dentro de un mismo trabajo se refleja esta alternancia de posiciones, que revela una inquietud nunca acabada. (2011: 374)

Mi esquema entonces sólo se justifica por razones de sistematización y no pretende encubrir las contradicciones que se dan en su interior. En una primera etapa se representa una sociedad escindida en la que se puede reconocer perfectamente, el habla de los indios, de los mestizos y de los señores. Arguedas, en "La novela y la expresión literaria del Perú" (2009 [1950]), dice: "Agua fue escrito con odio, con el arrebato de un odio puro; aquel que brota de los amores universales, allí, en las regiones del mundo donde existen dos bandos enfrentados con implacable crueldad, uno que esquilma y otro que sangra" (Arguedas, 2009 [1950]: 155). En efecto, en la siguiente cita, Arguedas dice que en Agua se presenta "la vida de una aldea andina" o de una "capital de distrito":

Allí no viven sino dos clases de gentes que representan dos mundos irreductibles, implacables y esencialmente distintos: el terrateniente convencido hasta la médula, por la acción de los siglos, de sus superioridad humana sobre los indios; y los indios, que han conservado con más ahínco la unidad de su cultura por el mismo hecho de estar sometidos y enfrentados a una tan fanática y bárbara fuerza. (2009[1950]: 155)

Está demás subrayar que en este mundo representado lo que predomina es o el monolingüismo de indios quechua hablantes y de "señores" hispanohablantes en cuyo espacio los mestizos actúan de traductores o un bilingüismo incipiente donde todavía se puede distinguir una lengua de la otra. Arguedas hace hablar a los indios y mestizos de un modo verosímil de manera que era 
imposible, en este periodo, que opte por un castellano más comprensible. Eso hubiera significado traicionar las peculiaridades linguiísticas de la aldea andina caracterizada justamente por la sintaxis "destrozada". En este mismo texto Arguedas sostiene que el destino de los mestizos en estas aldeas o capitales de distrito es irse, llegar a Lima y mantenerse en la capital a costa de los más duros sacrificios que incluyen sufrir el odio y el desprecio de los criollos. La otra salida del mestizo es actuar de manera hipócrita y cínica, esto es, engañar al terrateniente o "sangrar" a los indios.

En una segunda etapa, se amplía el mundo representado de las aldeas a lo que Arguedas llama los "pueblos grandes" o "capitales de provincia de la sierra”. En estos pueblos grandes ya no existen sólo indios, señores y mestizos, sino, según Arguedas, cinco personajes a los que posteriormente agrega un sexto que es el provinciano que migra a la capital, que invade Lima y cambia el rostro de la ciudad. Es muy lógico considerar que estos seis personajes tienen peculiaridades idiomáticas que Arguedas intenta representar de un modo verosímil. Esta ampliación del universo sociocultural, obviamente tiene su correlato en el universo sociolinguiístico que cada vez es menos monolingüe y más bilinguie de modo que ahora estamos frente a una mistura que se caracteriza por "sutiles desordenamientos" propios del mestizo, del estudiante, del migrante. Estos personajes, hablantes maternos de quechua, están influenciados fuertemente por procesos de castellanización. Citemos nuevamente a Arguedas:

Son cinco los personajes principales de los "pueblos grandes": el indio, el terrateniente de corazón y mente firmes, heredero de una tradición secular que inspira sus actos y da cimiento a su doctrina; el terrateniente nuevo, tinterillesco y politiquero, áulico servil de las autoridades; el mestizo de pueblo que en la mayoría de los casos no sabe adónde va; sirve a los terratenientes y actúa ferozmente contra el indio, o se hunde en la multitud, bulle en ella, para azuzarla y descargar su agresividad, o se identifica con el indio, lo ama y sacrifica generosamente su vida para defenderlo. El quinto personaje es el estudiante provinciano que tiene dos residencias, Lima y "su pueblo"; tipo generalmente mesiánico cuya alma arde entre el amor y el odio; este elemento humano tan noble, tan tenaz, tan abnegado, que luego es engullido por las implacables fuerzas que sostienen el orden social contra el cual se laceró y gastó su aliento. Sobre estos personajes fundamentales flotan las autoridades, cabalgan sobre ellos; y muchas veces, según su maldad, la indiferencia o rara buena intención de tales elementos, los pueblos se conmueven y marcan direcciones diferentes con pasos violentos o rutinarios. (2009 [1950]: 153-154)

El tercer momento es el de la síntesis de lo nacional. En este momento Arguedas intenta representar la compleja dimensión social de las lenguas en 
el Perú; esto es, las variaciones socio-demográficas del español y las lenguas nativas con los respectivos contactos linguísticos. Arguedas en este periodo ha desarrollado ya una lengua literaria nacional que va más allá del bilinguiismo quechua-castellano. En efecto, en este periodo Arguedas está interesado por el continuo dialectal social en el que los modos de hablar ubican a una persona dentro de una posición social de mayor o menor estatus. Alberto Escobar, refiriéndose al mundo linguíístico de El zorro de arriba y el zorro de abajo donde Arguedas presenta distintos castellanos dice: "Además esos actores se encuentran en distintos grados de apropiación de la segunda lengua, usada con una fuerte interferencia de su primera lengua, o sea de su lengua materna, que, por cierto, no es el castellano" (1984: 188). Chimbote o Lima son ciudades donde la comunicación se da básicamente en castellano, lo que no quiere decir que se hayan anulado los conflictos lingiísticos. Arguedas construye la mistura linguística "mezclando un poco" la sintaxis quechua con la castellana. Naturalmente este no es un solo castellano, sino una muestra de la variedad sociolinguística del español hablado en la costa peruana (Chimbote) con muchos ideolectos. Este registro representa bien el habla de los migrantes en las ciudades de la costa y sierra del Perú. En ese mismo sentido va la opinión de Dora Sales de quien es la siguiente cita:

Con todo, la lengua narrativa del último texto arguediano, la novela El zorro de arriba y el zorro de abajo (1971, póstuma), plantea una radical innovación formal que afecta tanto al argumento como al lenguaje. Al reflexionar desde la ficción, y paralelamente desde la antropología, sobre la migración de los campesinos serranos a la costa del Perú, Arguedas fluctuó entre el optimismo ante el encuentro de dos mundos y el pesimismo por las imposiciones sobre el universo cultural andino. En este último texto, ese encuentro cuerpo a cuerpo, que Arguedas había narrado desde el comienzo de su trayectoria, se intensifica. Aquí Arguedas utiliza un procedimiento discursivo totalmente distinto: el lenguaje es el camino principal para hablar de los diferentes contextos de los personajes. No trasmite un mundo cultural diferente a través del lenguaje, traduciéndolo, sino que ese mundo está plasmado explícitamente en el lenguaje del El zorro de arriba y el zorro de abajo. Arguedas modifica y adapta el lenguaje más fluido que había elaborado en Los ríos profundos y Todas las sangres. Elabora, en la voz de los diversos personajes, un castellano mucho más cargado de quechuismos, y recalca diferencias linguiísticas que atienden a la geografía y a la clase social de los hablantes (2009: 27).

Quiero resaltar tres ideas planteadas por Sales que me parecen fundamentales. Por un lado el hecho de que el lenguaje sea uno de los principales protagonistas de la novela porque delata los diferentes contextos socio-linguiísticos 
y culturales de los personajes; por otro lado, está la intensificación del conflicto cultural y linguíístico en la novela póstuma de Arguedas y, finalmente, la elaboración de un "castellano mucho más cargado de quechuismos". ¿Cómo se puede sostener que el proyecto está acabado con Los ríos profundos? Una cita más para reforzar la idea de que el proceso de construcción del lenguaje "misturado" continúa después de Los ríos profundos la corresponde esta vez a Antonio Melis.

Un elemento constante de este recorrido, interrumpido solo por el suicidio, es el rechazo de cualquier solución banalmente mimética. Asistimos, en cambio, a la transformación del español de base a través de la progresiva invasión de los modos sintácticos de la lengua indígena. Hasta llegar, con El zorro de arriba y el zorro de abajo -la novela que narra al mismo tiempo una historia ambientada en un gran puerto pesquero del norte del país y anuncia una decisión irrevocable de matarse -, a una autentica polifonía, no exenta de disonancias (2011: 268).

En sentido contrario, Jana Hermuthová ha planteado que El zorro de arriba y el zorro de abajo representa la renuncia de Arguedas a seguir construyendo, esta vez mezclando muchas más lenguas, la lengua literaria llamada "mistura". La autora cree que el proyecto ha llegado a su fin y que es el propio Arguedas el encargado de destruir el "[...] ideal utópico, construido con tantos años de esfuerzo" (2004: 58) porque: "La cultura oral de los indígenas, que pierde sus raíces y se disuelve en la hirviente modernidad de un puerto pesquero, afecta al autor hasta tal punto que no se siente capaz de expresar la complejidad de un mundo tan desarticulado" (2004: 58). Hablar de incapacidad de comunicar o de resignación ante la posibilidad de unir (ya no solamente al quechua y castellano) todas las culturas y lenguas peruanas es, por decir lo menos, desconocer el proyecto cultural y linguístico arguediano. Por el contrario, el proyecto utópico se amplía de modo que ahora se plantea la integración de todas las etnias, lenguas y culturas peruanas. En la novela póstuma de Arguedas hay una ampliación del universo linguiístico representado que es un reflejo de los pobladores que llegan de todas partes a Chimbote. Ciertamente construir un lenguaje con más de dos lenguas es un proyecto mucho más complicado que hacerlo con sólo dos lenguas. Cito otra vez a Hermuthová para tener una idea más clara de su planteamiento:

Lo mismo ocurre con el lenguaje. El discurso que debía expresar la diferenciación de la vida en Chimbote desemboca en un nudo de palabras impenetrable, en un caos babélico difícil de comprender a causa de las dificultades linguíísticas. Se ve claramente que también Arguedas sobrepasaba estos fragmentos con mucha dificultad. (2004: 60)

Recordemos que Arguedas, en 1950, declara que no es partidario de la "indigenización" del castellano. "¿Es que soy acaso un partidario de la "indi- 
genización' del castellano? No. Mas existe un caso, un caso real en el que el hombre de estas regiones, sintiéndose extraño ante el castellano heredado, se ve en la necesidad de tomarlo como elemento primario al que debe modificar, quitar y poner, hasta convertirlo en un instrumento propio". (2009 [1950]: 157) Tenemos entonces que Arguedas reconoce que es el castellano y no el quechua el idioma que debe servir de base para la creación de nuestra expresión y esto supone reconocer también las pérdidas, los "desgarramientos" así como las ganancias para el idioma. Este planteamiento linguíístico no corresponde con sus opiniones sobre el mestizaje donde, más bien, la cultura base, la matriz cultural debe ser la india.

Creo que en la novela Los ríos profundos este proceso ha concluido. Uno solo podía ser el fin: el castellano como medio de expresión legítimo del mundo peruano de los Andes; noble torbellino en que los espíritus diferentes, como forjados en estrellas antípodas, luchan, se atraen, se rechazan y se mezclan, entre las más altas montañas, los ríos más hondos, entre nieves y lagos silenciosos, la helada y el fuego. (Arguedas, 2009 [1950]: 160)

Que Arguedas asuma que el castellano debe ser el idioma base en la expresión literaria peruana no implica necesariamente que opte un tipo de castellanización que anule a las lenguas nativas. Más bien creo que Arguedas opta por un castellano andino profundamente influenciado por un sustrato quechua o aymara. En ese sentido, no creo pertinente leer su voto a favor del castellano como una abdicación a la "mistura" linguiística.

Klaus Elmar Schmidt (2005) añade al debate sobre a lengua arguediana, justamente la idea de que Arguedas "indigenizó" la lengua europea para permitir alcanzar un número mayor de lectores. Esto sólo se puede hacer en el campo de la creación literaria puesto que es el lenguaje literario el único que permite transmitir la propia experiencia cultural indígena a una lengua europea modificada. Indiscutiblemente esto implica adaptar, adecuar, acomodar o ajustar, más que traducir, los componentes linguiísticos de la lengua nativa. En efecto, cuando Arguedas opta por el castellano como idioma base, no está aceptando un castellano normativo o una variedad estándar del mismo; más bien, se está apropiando del castellano andino con el fin de transmitir en él la cosmovisión de la cultura nativa; cuestión que no necesariamente tiene que ser vista como "traducción”. Entonces, ¿qué significa para Arguedas la "indigenización” del castellano? Y ¿por qué no la acepta? Lo primero que quiero anotar es: "No. Mas existe un caso" es decir la relativización de su negación. En consecuencia es probable que Arguedas haya visto la indigenización como la incrustación de elementos linguiísticos quechuas como palabras, frases, oraciones y hasta textos dentro del castellano sin que estos lleguen a integrarse plenamente 
dentro de la estructura de la lengua receptora. Jana Hermuthová sostiene que Arguedas se diferencia de aquellos escritores que solamente tratan de "salpicar la novela de palabras indígenas y añadir un glosario al final o bien utilizar un dialecto local" (2004: 41). Estos escritores, que no saben una lengua indígena, no son capaces de concebir y construir un lenguaje literario por lo que se limitan a utilizar quechuismos y regionalismos a veces incomprensibles. Es posible también que la indigenización signifique para Arguedas la representación "carnavalesca" del habla de los pobladores andinos de modo que se altere y manipule el habla de los indios y mestizos. .

Arguedas se preocupa no sólo por representar todos los registros linguiísticos, incluyendo las formas de hablar de extranjeros, sino por construir una lengua mestiza / lengua mezclada / lengua combinada /lengua heterogénea / lengua híbrida / lengua atravesada / lengua cruzada / lengua transculturada que sea la lengua peruana. El problema de la expresión literaria en Arguedas se resume en la pregunta sobre cómo debía hacer hablar de modo verosímil a los indios y mestizos en sus relatos sin descuidar los otros registros sociolinguiísticos. Entonces tenía las siguientes opciones que fueron todas experimentadas y trabajadas por él.

\section{Opciones arguedianas}

La primera opción consistía en hacer hablar a los indios y mestizos en quechua. Esto es reflejar y registrar el idioma de los indios y traspasarlo a la literatura con la necesidad de notas de "traducción" para lectores no competentes en quechua. Aquí también podemos hablar de un proceso aparentemente contradictorio que, desde mi punto de vista, evidencia los conflictos de un bilinguie. Arguedas en "Canto kechwa. Con un ensayo sobre la capacidad de creación artística del pueblo indio y mestizo" (2004 [1938]) dice: "No encontré ninguna poesía que expresara mejor mis sentimientos que la poesía de las canciones kechwas. Los que hablamos este idioma sabemos que el kechwa supera al castellano en la expresión de algunos sentimientos que son los más característicos del corazón indígena: la ternura, el cariño, el amor a la naturaleza" (2004 [1938]: 100). Para Arguedas el quechua expresa las emociones, los sentimientos con igual o mayor intensidad que el castellano lo que lo convierte en un idioma muy afectivo ${ }^{6}$. Veamos la siguiente cita de Arguedas:

6 Arguedas en "La literatura quechua en el Perú" recalca la idea cuando dice: "Esta superación es posible porque el quechua es, por su propia naturaleza, un medio de expresión más íntimo, más cargado de símbolo y de aliento, para la traducción de algunos sentimientos humanos que son predominantes y característicos de los pueblos agrícolas; tal la ternura: himnos al niño Jesús, a la Virgen, al Cristo crucificado y sangrante; himnos de gratitud o de imploración: oración al amanecer; cantos para aplacar la ira de los elementos" ( 2004 [1948]: 154-155). 
A pesar de los 400 años de persecución a que ha hecho frente, el kechwa no ha perdido su vitalidad. En el Perú la mayor parte del pueblo habla kechwa; y si bien el idioma ha perdido su pureza, a tal punto que el kechwa primitivo resulta ya difícil para los que hablamos el actual, en cambio se ha enriquecido con palabras castellanas, que ha incorporado reduciéndolas a la morfología kechwa. El Kechwa es un idioma suficientemente rico para la expresión del hombre superior. En circunstancias propicias podrá dar una gran literatura. Y matarlo ha de ser muy difícil. (2004 [1938]: 100-101).

En esta cita aparecen seis ideas de lo más interesantes. 1. El quechua es un idioma vital hablado, en 1938, por la mayoría de los peruanos. 2. El quechua ha perdido su pureza de modo tal que resulta difícil, sino imposible, hablar de un quechua primitivo o puro. 3. Hay un quechua actual que se ha enriquecido con palabras castellanas adaptadas a la morfología y fonética quechua. 4. El quechua es un idioma "suficientemente rico" para la expresión del "hombre superior”. Pero, ¿quién es el hombre superior y quién el hombre inferior? 5. Que el quechua podrá dar una gran literatura implica o que no ha habido una literatura quechua importante o que no la hay hasta el momento de publicación de este texto. Sin embargo, para entender esta cita, debemos tener en cuenta que lo que Arguedas está reclamando es una estandarización, y por lo tanto una democratización, de la escritura quechua que permita la producción de una literatura escrita en quechua. Esto supone sacar al quechua de reducto oral y plantear un proyecto escritural. 6. Cuando Arguedas afirma que matar el quechua ha de ser muy difícil, está evidenciando que el quechua está vivo también dentro del castellano. La siguiente cita extraída de "Ensayo sobre la capacidad de creación artística del pueblo indio y mestizo" (2011 [1938] Arguedas evidencia que el quechua es el idioma en el que se desahogan o en el que mejor expresa sus sentimientos los señores principales:

El kechwa logra expresar todas las emociones con igual o mayor intensidad que el castellano. Los mismos principales, despreciadores del indio, cuando sienten una gran emoción dejan el castellano para hablar en kechwa, y en ese rato se desahogan con más violencia, como quien habla con sus propias palabras.7 (2011 [1938]: 133)

Un año antes, Arguedas, en su artículo "Entre el kechwa y el castellano, la angustia del mestizo" (2009 [1939]), consideraba que el quechua era el medio legítimo de expresión del indio y del mestizo. "Pero si escribimos en kechwa hacemos literatura estrecha y condenada al olvido". (2009 [1939]: 142). Hago notar aquí que Arguedas está pensando en lo que Pierre Bourdieu (1985 y 2002) ha llamado el mercado lingüístico que evidencia la desigualdad de las manifestaciones verbales que funcionan como mercancías más o menos valiosas debido a su institucionalización, prestigio social, radio de acción, difusión edi- 
torial, etc., que a su vez permiten las relaciones de dominación linguiística. En ese mismo texto Arguedas dice: "Y el kechwa, que es todavía su idioma genuino, con el que habla en la medida de sus inquietudes y con el que describe su pueblo y su tierra hasta colmar su más honda necesidad de expresión, es idioma sin prestancia y sin valor universal" (2009 [1939]: 143). Por lo menos hasta 1939, Arguedas consideraba al quechua como un idioma "sin prestancia", "sin valor universal" y como un idioma estrecho en la que se produce o una mala literatura o una literatura "condenada al olvido". El uso del quechua "puro" o "primitivo" limitaba enormemente las posibilidades de comunicación y de entendimiento de los lectores en un mercado linguístico dominado por el castellano. La opción por el monolingüismo requería la mediación de la traducción y limitaba las posibilidades de universalización de la literatura. Algunos críticos, entre los que se encuentra Mario Vargas Llosa, han visto en esta representación una especia de lengua provincial, localista que impide la universalización de su narrativa. Entonces se hace imprescindible tener claro que lo que Arguedas escribe con su peculiar estilo es la representación de lo que se habla en los Andes. La idea de un quechua reducido, estrecho, íntimo y sin horizonte le preocupa a Arguedas de modo angustiante.

Posteriormente, en los tres artículos titulados "La canción popular mestiza e india en el Perú, su valor documental y poético" (1989) que fueron escritos entre 1940 y 1941 Arguedas dice que el wayno es indio y mestizo, que kilko Waraka y Gabriel Aragón, dos conocidos poetas y cantores quechuas, son mestizos que representan la vida del pueblo indio y que Lima se ha convertido en la ciudad más andina del Perú. Quiero hacer notar que en este artículo Arguedas da la misma importancia al mestizo y al indio. Es más, hay una cierta inclinación a lo mestizo cuando deja de lado los problemas linguiísticos de los hablantes monolinguies quechuas y centra su atención en los conflictos y angustias de los mestizos bilinguies. Pero en 1944, Arguedas escribe "El valor poético y documental de los himnos religiosos quechuas" (1989 [1944]) donde dice que, los misioneros que hablaron en un quechua excelso en el que predicaron, "tradujeron al quechua los principios fundamentales del catolicismo, los rezos, plegarias y cánticos más importantes; crearon nuevos cantos y oraciones en quechua, y predicaron en lengua nativa” (1989 [1944]: 137). Transcribo además la siguiente cita: "Porque estos himnos son la muestra más perfecta del quechua clásico que heredaron los misioneros, y que ellos mejoraron, porque le infundieron categoría para la expresión del pensamiento abstracto" (1989 [1944]: 138). No comentaré aquí el desliz arguediano sobre el "pensamiento abstracto". Arguedas era consciente de que la literatura quechua que nos llegó a través de sacerdotes católicos, misioneros y adoctrinadores era ya una literatura quechua influenciada por el catolicismo y la cultura hispana. Es más, en su 
artículo "La literatura quechua en el Perú" (2004 [1948]) considera que. "En lo que se refiere a la conservación de la lengua quechua, los años de la conquista y la época colonial fueron periodos positivos y aún podríamos considerarlos fecundos. No fueron siglos de destrucción para este elemento fundamental de la cultura incaica" (Arguedas, 2004 [1948]: 152). En este mismo artículo sostiene que los doctrineros y misioneros fundaron la literatura quechua escrita que tuvo temas católicos, tuvieron un alto grado de comprensión de la cultura india, conocieron la psicología del indio, experimentaron una capacidad de adaptación y de auto inclusión que les permitió convivir de un modo íntimo con los indios, demostraron un envidiable dominio de la estética quechua y, como consecuencia de lo anterior, compusieron himnos, oraciones, cantos adaptándolos a los géneros más adecuados de la música indígena.

Las citas anteriores demuestran que Arguedas era consciente de la inexistencia de un "quechua puro" y que el quechua está "misturado" Arguedas no consideró jamás que la literatura quechua escrita era propiedad de los "indios puros" porque estos, para escribir, habían sufrido procesos de transculturación. En su texto: "Canciones y cuentos del pueblo quechua" (2004 [1949]), Arguedas (o el yo enunciador) se identifica como mestizo y blanco: "Nosotros, los mestizos y blancos“ (2004 [1949]: 164) y después evidencia su tipo de bilingüismo cuando dice: "Desearía manifestar que yo aprendía a hablar en quechua. Después de 25 años de intenso trabajo y estudio creo haber logrado un dominio equivalente del castellano, en forma y espíritu” (2004 [1949]: 166).

Hacerlos hablar en castellano constituía la segunda opción. Pero esto significaba tergiversar cuando no traicionar la lengua, la identidad, la cultura y tergiversar también el universo representado. Arguedas dice: "Si hablamos en castellano puro, no decimos ni del paisaje ni de nuestro mundo interior" y "Cuando empecé a escribir, relatando la vida de mi pueblo sentí en forma angustiante que el castellano no me servía bien” (2009 [1939]: 142).

Escribí el primer relato en el castellano más correcto y "literario" de que podía disponer. Leí después el cuento a algunos de mis amigos escritores de la capital, y lo elogiaron. Pero yo detestaba cada vez más aquellas páginas. iNo, no eran así ni el hombre, ni el pueblo, ni el paisaje que yo quería describir, casi podría decir, denunciar! Bajo un falso lenguaje se mostraba un mundo como inventado, sin médula y sin sangre; un típico mundo "literario", en que la palabra ha consumido a la obra. Mientras en la memoria, en mi interior, el verdadero tema seguía ardiendo, intocado. Volví a escribir el relato y comprendí definitivamente que el castellano que sabía no me serviría si seguía empleándolo en la forma tradicionalmente literaria. Fue en aquellos días que leí Tungsteno de Vallejo y Don Segundo Sombra de Güiraldes. Ambos libros me alumbraron el camino. (Arguedas, 2009 [1950]: 156-157) 
A diferencia del Inca Garcilaso de la Vega que logra expresar en un castellano limpio y castizo la cultura quechua de la que mamó cuando niño, Arguedas siente que no domina el castellano y que está en ese proceso. Además, para Arguedas hay una estrecha relación entre lengua y cultura o entre significantes y significados porque también cuentan los aspectos fonéticos y la expresión de tonalidades propias del mundo andino. Arguedas no consideró, como el Inca, que era un bilinguie coordinado a pesar de que su destreza en español era más que aceptable como lo demuestra su escritura en español. Arguedas, por el contrario, se consideraba un bilingüe subordinado con predominancia quechua.

La tercera opción planteaba el reto de recrear el bilingüismo que se manifiesta cotidianamente en los Andes. Bilingüismo donde se expresa la "mistura" o la "fusión" del quechua y el castellano. Para Arguedas tenemos la posibilidad y la necesidad de recrear un castellano popular que resuelva el complejo problema del bilingüismo o multilinguiismo en el Perú. Tarea dura y difícil dado que se trata de convertir un idioma ajeno en propio, se trata de comunicar en una lengua la materia, el alma, el espíritu de nuestro pueblo, se trata de que el castellano esté contaminado del quechua hasta el punto de volverlo una lengua nueva "iSe trata de no perder el alma, de no transformarse por entero en esta larga y lenta empresa!" (2009 [1950]: 159) y "No se trata, pues, de una búsqueda de la forma en su acepción superficial y corriente, sino como problema del espíritu, de la cultura" (2009 [1950]: 160). Para algunos autores como Jana Hermuthova, y para el propio Arguedas, este es el punto de llegada o el punto culminante del proceso experimental que se consuma en Los ríos profundos. Hermuthova cree necesario distinguir entre lenguaje mestizo y lenguaje transculturado ${ }^{7}$.

Así no surge un lenguaje mestizo, sino el español transculturado nutrido del espíritu quechua. El esfuerzo por encontrar el nuevo estilo desemboca en la novela Los ríos profundos. Nos hablan en un castellano simple, concentrado y elaborado, por medio del que se traduce no sólo el idioma quechua, sino toda la cultura indígena. En el nuevo lenguaje se refleja la actitud rigurosa de Arguedas hacia la palabra que se despoja tanto de los regionalismos como de la transformación superficial del idioma ( 2004: 50).

La pregunta es: ¿este punto culminante continúa en Todas las sangres y en $E l$ zorro de arriba y el zorro de abajo? Nosotros creemos que no sólo continúa, sino

7 Jana Hermuthová en "El discurso experimental arguediano" (2004) dice "José María Arguedas elaboró un español nutrido de la sintaxis, el ritmo, la melodía, la ternura y la sensibilidad de la lengua autóctona. Es un español transculturado, cuyo carácter bicultural debe servir como representación fiel del mundo quechua. Sin embargo, aún se encuentra otro significado en su mensaje. Se establece como puente de comunicación entre dos culturas en conflicto" (24). 
que se complejiza aún más por la ampliación de los mundos representados. Sin embargo, Tarica y Hermuthová sostienen que en este periodo Arguedas se arrepiente, renuncia y destruye su esfuerzo por construir una lengua literaria misturada. Veamos la siguiente cita de Arguedas:

¿En qué idioma se debía hacer hablar a los indios en la literatura? Para el bilingüe, para quien aprendió a hablar en quechua, resulta imposible, de pronto, hacerles hablar en castellano; en cambio quien no los conoce a través de la niñez, de la experiencia profunda, puede quizá concebirlos expresándose en castellano. Yo resolví el problema creándoles un lenguaje castellano especial, que después ha sido empleado con horrible exageración en trabajos ajenos. iPero los indios no hablan en ese castellano ni con los de lengua española, ni mucho menos entre ellos! Es una ficción. Los indios hablan en quechua. [...] Es, pues, falso y horrendo, presentar a los indios hablando en el castellano de los sirvientes quechuas aclimatados en la capital. Yo, ahora, tras dieciocho años de esfuerzo, estoy intentando una traducción castellana de los diálogos de los indios. La primera solución fue la de crearles un lenguaje sobre el fundamento de las palabras castellanas incorporadas al quechua y el elemental castellano que alcanzan a saber algunos indios en "sus propias aldeas". La novela realista al parecer, no tenía otro camino. (2009 [1950]: 159)

Una primera cuestión a tener en cuenta es que este texto es de 1950. En esta época se habían iniciado los procesos sociales de movilidad social, pero todavía se podía apreciar un país escindido entre indios y blancos. Los indios asociados a las lenguas nativas y a la sierra y los blancos asociados al español y a la costa. Ahora, en cambio, es perfectamente posible encontrar estereotipos que rompen la dualidad de antaño. Una segunda cuestión que se deriva de la cita anterior tiene que ver con la frases "hacer hablar a los indios en la literatura" lo que nos remite al terreno de la ficción y de los mundos posibles. Además, "hacer hablar" implica una dependencia, una subordinación de expresión india a la voz y la expresión del constructor de la ficción que es el novelista. La cuestión entonces es cómo hacer hablar a los indios en la literatura sin traicionar su lengua nativa y, a la vez, sin hacerla inentendible. La tercera idea expresada aquí se refiere a la verosimilitud de la lengua en la que se "hace hablar" a los indios en la literatura. En efecto, y desde el punto de vista de un lector competente de los años 50 que además conoce el mundo andino, es poco verosímil que un indio se exprese en castellano. La cuarta cuestión tiene que ver con el artificio, con la creación de un "castellano especial" que represente el habla de los indios de modo tal que sea entendible por los lectores hispanohablantes haciendo que estos identifiquen a los personajes indios como quechua hablantes. No quiero dejar pasar la denuncia de Arguedas a aquellos escritores que "con horrible exageración" tergiversan el habla de los indios y de los mestizos. 


\section{¿Y la poesía?}

Los estudios sobre la lengua arguediana pecan al dejar de lado el estudio de su poesía ${ }^{8}$. Ya en el 2005 Antonio Melis decía: "De toda la obra multifacética -y al mismo tiempo profundamente unitaria- de José María Arguedas, la parte menos estudiada por la crítica sigue siendo hasta hoy la poesía" (2011: 333). La escritura de los poemas demostraría que Arguedas finalmente optó por escribir en quechua o que el quechua finalmente salió triunfante en el conflicto linguiístico y cultural. Esto indicaría también una evolución interesante en relación a la importancia que le da al radio de influencia del idioma. Así, de un Arguedas preocupado por las limitaciones del quechua y por construir un lenguaje misturado que permita tener un mayor público lector se pasa a un Arguedas que finalmente decide escribir en quechua El sueño del pongo en 1965 y en un quechua misturado, que toma en cuenta varios dialectos para hacerlo entendible a todos los hablantes y lectores de todas las variedades del quechua, los poemas de Katatay (1972). Cito nuevamente la lucidez de Antonio Melis:

Lo que parece indudable es el hecho de que el camino literario le proporciona a Arguedas los momentos más eufóricos, a través de la experimentación concreta de grandes posibilidades del idioma indígena. La culminación de este proceso se realiza, sin dudas, en la decisión de escribir, en los últimos años de su vida, los poemas en quechua que serán recopilados, después de su muerte, en Katatay (1972). Al mismo tiempo esta auténtica hazaña no detiene su inquietud que lo lleva a seguir su "pelea verdaderamente infernal con la lengua", a la que había aludido en el conocido Primer Encuentro de Narradores Peruanos de Arequipa de 1965, hasta las páginas desgarradoras de su novela póstuma” (2001: 374)

Entonces, el proceso evolutivo tendría no tres, sino cuatro etapas o momentos $^{9}$. Contraria a la opinión de Estelle Tarica quien sostiene que el proceso

8 Mauro Mamani Macedo acaba de publicar un ensayo sobre la poesía arguediana. José María Arguedas. Urpi, fieru, quri, sonqoyky. Lima, Petróleos del Perú, 2011.

9 Carlos Huamán en su libro Pachachaka. Puente sobre el mundo: narrativa, memoria y símbolo en la obra de José María Arguedas (2004) propone los siguientes momentos:

1) La utilización de un "castellano correcto" con "sutiles desordenamientos" en "Agua", al igual que en "Warma Kuyay", le sirve al autor como modelo para utilizar la mistura en Yawar Fiesta. Esta mezcla quechua-castellano está relacionada con la realidad linguiística de la sierra peruana (aldea y provincia), por lo que Arguedas considera la necesidad de insertar la cultura quechua en el sistema linguiístico castellano, para ampliar el campo de recepción y buscar la universalidad partiendo de lo local. Este hecho nos sitúa en el campo del mestizaje linguiístico, asunto que el autor abordará desde diferentes ángulos en sus obras posteriores.

2) Arguedas realiza una búsqueda del perfeccionamiento del castellano para sus relatos con el objetivo de recrear la cultura quechua. Opta por conquistar a lectores no quechua hablantes mediante el rescate de la entonación linguística del runa simi y la connotación de algunas palabras de ese mundo, abriendo así la posibilidad de hablar de la cultura a través de recur- 
va de la mistura a la traducción y un tanto a favor de la opinión de Aymará de Llano (2010) quien más bien habla de un "efecto de traducción" más que de traducción en sentido estricto, yo sostengo que el proceso más bien va de la "traducción" a la mistura castellana y quechua; esto es desde la predominante expresión monolinguie mediada por la "traducción" que, en un segundo momento, pasa por la expresión bilinguie hasta llegar al multifacético rostro linguiístico de la sociedad peruana que derivará después en lo que Ángel López García (2008) ha denominado el sesquilingüísmo. En efecto, Arguedas es sesquilinguie incluso cuando escribe en quechua misturado los poemas de Katatay. El prefijo sesqui significa "uno y medio". Así, una persona es sesquilingüe cuando en ella conviven dos lenguas de manera muy especial. Una lengua dominante en la que se comprende, habla y, sobre todo, escribe; y una lengua dominada que se comprende, se puede o no hablar, pero que difícilmente se escribe por varias razones entre las cuales la fundamental es la falta de una normativización del sistema escritural. ¿Quiénes son los escritores sequilingüies? Se trata -dice Ángel López García- de escritores que son bilinguies, pero que no pueden escribir en la lengua "nativa" o "dominada" porque ésta carece de normativización y, además, porque carecen de un número suficiente de personas alfabetizadas. En consecuencia, escriben en la lengua dominante de modo que podrían ser considerados traidores a la cultura o lengua nativa. Cito a López García:

José María Arguedas no era un hablante sesquilinguie, no hablaba español y comprendía quechua, sino que se trataba de una persona plenamente bilingüe; que hablaba y entendía tanto el español como el quechua. Sin embargo, literariamente su obra es sesquilinguie: está escrita en español, pero refleja ambos mundos, el mundo hispanohablante y el mundo quechuahablante. Quisiera hacer aquí una importante precisión. A veces se confunde a Arguedas con los llamados escritores indigenistas, con Miguel Ángel Asturias, con Rómulo Gallegos, con Ciro Alegría. No hay tal. Estos escritores reflejan, en efecto, los dos mundos, el hispano y el indígena (guatemalteco, venezolano, peruano), pero del lado indígena se trata de un mundo cultural, no de un mundo linguíístico. (2008: 101-102)

sos simbólicos de carácter mágico, mítico y poético. Es el caso de Los ríos profundos.

3) En Todas las sangres se potencializa la presencia de los símbolos. El escenario reúne la diversidad linguística peruana en proceso de mestización y se plantea la continuidad de la cultura quechua-andina.

4) En El zorro de arriba y el zorro de abajo, cuyo escenario es Chimbote, ubicado en la costa peruana, se plantea el rescate de la heterogeneidad linguiística y la diversidad de orientaciones culturales de Perú. Rescata el carácter oral del castellano hablado en dicho lugar y llega a subvertir el canon novelesco de la época. Indudablemente la multifacética realidad linguiística de Los zorros... alude a un mestizaje complejo de diferente nivel y en diferentes direcciones. (2004: 106). 
Para Ángel López García, cuando Arguedas escribe en español deja resonar o traslucir el quechua en su obra. Mejor aún, evidencia un universo bilingüe en el que se integran los sistemas culturales y linguísticos quechua y español de modo que el lector asuma que está frente a un mundo narrado bilinguie y bicultural. "La diferencia entre un universo narrativo bilingüe y un universo narrativo construido por un bilingüe, es capital. Arguedas no novela un mundo que, además, es bilingüe, sino que novela la cognición dividida bilingüe de dicho mundo" (2008: 106). Esto quiere decir que Arguedas no sólo representa el universo bilinguie del mundo andino, sino que lo hace desde la perspectiva de un narrador bilinguie. En el importante artículo de López García se enumeran los procedimientos del Arguedas sesquilinguie en Los ríos profundos que a saber son: a) La versión bilinguie de canciones y otros recitados populares. b) La aclaración etimológica por algunos de los personajes de determinados nombres propios que aparecen en el texto. c) La aclaración etimológica de un nombre propio por el autor. d) La paráfrasis traductológica de un nombre relevante por parte del autor, lo cual conduce en ocasiones a documentadas y extensas notas lexicográficas insertadas en el texto. e) secuencias en la lengua quechua, seguidas de su equivalente en la lengua española. f) Secuencias en la lengua quechua con su equivalente en español y una explicación relativa a sus valores contextuales en nota a pie de página. g) Secuencias en español, que se anuncian como dichas en quechua, con su equivalente original en nota a pie de página. h) Secuencias en español que se anuncian como dichas en quechua, pero sin traducción; normalmente buscan cierta complicidad con el lector porque el interlocutor no las comprende. i) Alusiones a la pronunciación de algún fragmento en lengua quechua (2008: 102-104).

La mistura de la lengua se produce por el conflicto linguíítico real que tienen el indio, el mestizo o "el hombre del Ande" respecto de la lengua en la que deben expresarse que puede ser el castellano como lengua impuesta en la escuela, en el colegio o la universidad que "no le sirve bien para decir en forma plena y profunda su alma o el paisaje del mundo donde creció" (Arguedas, 2009 [1939]: 143), el quechua como lengua propia reducida a espacios comunicativos familiares, comunales o una lengua que sea un "equilibrio" ente ambas que haga universal lo local. Arguedas dice que el mestizo o el hombre del Ande tiene una especie de desesperación por dominar el castellano

De aquí nace el ansia actual del mestizo por dominar el castellano. Pero cuando lo haya logrado, cuando pueda hablar y hacer literatura en castellano con la absoluta propiedad con la que ahora se expresa en kechwa, ese castellano ya no será el castellano de hoy, de una insignificante y apenas cuantitativa influencia kechwa, sino que habrá en él mucho de genio y quizá de la íntima sintaxis kechwa. Porque el kechwa, expresión 
legítima del hombre de esta tierra, del hombre como criatura de este paisaje y de esta luz, vive en el mestizo como parte misma, y esencial, de su ser y de su genio.

Esta ansia de dominar el castellano llevará al mestizo hasta la posesión entera del idioma. Y su reacción sobre el castellano ha de ser porque nunca cesará de adaptar el castellano a su profunda necesidad de expresarse en forma absoluta, es decir, de traducir hasta la última exigencia de su alma, en la que lo indio es mando y raíz (2009 [1939]: 143).

Arguedas sostiene que el conflicto o angustia del mestizo que se encuentra entre el quechua y el castellano surge de la mala literatura en castellano que se ha hecho en la sierra del Perú. Una literatura intrascendente por desarraigada e insensible, sin posibilidad de representar el "alma" de pueblo andino. Esto le permite concluir que, por un lado, el "castellano puro" no es el idioma apropiado para la expresión del indio y, por otro lado, que el "castellano puro" no es el idioma apropiado para la expresión del mestizo puesto que en el mestizo es más lo indio que lo español. ¿Cuál es el idioma apropiado para la expresión del mestizo y del mundo andino que no es sólo indio aunque sea predominantemente indígena? Arguedas reconoce que las escasas obras literarias que se han producido en la sierra y tienen algún mérito son aquellas en las que el castellano está influenciado por el quechua. Las más, aquellas que no tienen trascendencia, son aquellas que se han escrito en medio ilegítimo de expresión que es el "castellano puro".

Estamos asistiendo aquí a la agonía del castellano como espíritu y como idioma puro e intocado. Lo observo y lo siento todos los días en mi clase de castellano del colegio Mateo Pumacahua, de Canchis. Mis alumnos mestizos, en cuya alma lo indio es dominio, fuerzan el castellano, y en la morfología íntima de ese castellano que hablan y escriben, en su sintaxis destrozada, reconozco el genio del quechua (Arguedas, 2009 [1939]: 144).

Para esta segunda parte debemos establecer también algunas conclusiones. Habíamos dicho que Arguedas era - aunque no se considerara- un bilinguie coordinado y un hombre bicultural, que no creía que la literatura peruana debía ser escrita ni en un castellano estándar o castizo, ni en un quechua "puro" puesto que los dos idiomas habían sufrido procesos de trasnlingüístización, que el lenguaje literario peruano debía ser uno misturado. Como complemento de lo anterior evidenciamos ahora el proceso de misturización que va desde un mundo representado prioritariamente monolinguie o con un bilingüismo incipiente al que le sigue un mundo andino representado con mayor complejidad donde predominan los procesos de transculturación y movilidad social que se manifiestan en un sujeto mestizo y una lengua misturada básicamente 
quechua-española, hasta llegar a u mundo donde se representa la complejidad de lo nacional que trasciende el bilingüismo quechua-castellano e intenta representar la complejidad del multilingüismo en un país pluricultural que sufre procesos violentos de mezcla como consecuencia de los procesos de migración masiva. En línea paralela Arguedas no renuncia a producir una literatura quechua escrita, especialmente lírica, en un quechua misturado o en una lengua franca quechua. La poesía de Arguedas que es su expresión lírica y no narrativa se escribe en quechua y no en castellano, pero este quechua tampoco es puro. Así, creo haber demostrado que el proceso va de la traducción a la mistura y que este proceso no termina ni se anula con Los ríos profundos.

\section{Referencias bibliográficas}

ARGUEDAS, José María (1957). "Evolución de las comunidades indígenas. El valle del Mantaro y la ciudad de Huancayo: un caso de fusión de culturas no comprometidas por acción de las instituciones de origen colonial”. Revista del Museo Nacional. Tomo XXVI. Lima; pp. 78-151.

ARGUEDAS, José María (1972). Temblar / Katatay y otros poemas. Lima: Instituto Nacional de Cultura.

ARGUEDAS, José María (2006) [1975]. Formación de una cultura nacional. México D. F.: Siglo XXI editores.

ARGUEDAS, José María (1989). Indios, mestizos y señores. Lima: Editorial Horizonte.

ARGUEDAS, José María (1989) [1965]. "El indigenismo en el Perú". En Arguedas, José María, Indios, mestizos y señores. Lima: Editorial Horizonte; pp. 9-20.

ARGUEDAS, José María (1989) [1940]. "El charango". En Arguedas, José María, Indios, mestizos y señores. Lima: Editorial Horizonte; pp. 41-44.

ARGUEDAS, José María (1989) [1940a]. "La canción popular mestiza e india en el Perú, su valor documental y poético”. En Arguedas, José María, Indios, mestizos y señores. Lima: Editorial Horizonte; pp. 45-47.

ARGUEDAS, José María (1989) [1944]. "El valor documental y poético de los himnos religiosos quechuas". En Arguedas, José María, Indios, mestizos y señores. Lima: Editorial Horizonte; pp. 137-140.

ARGUEDAS, José María (2004). ¿Kachkaniraqmi! ¿Sigo siendo! Textos esenciales. (Recopilación y notas de Carmen María Pinilla). Lima, Fondo editorial del Congreso del Perú.

ARGUEDAS, José María (2004). "Canto kechwa: Con un ensayo sobre la capacidad de creación artística del pueblo indio y mestizo". En Arguedas, José María, ¿Kachkaniraqmi! ¿Sigo siendo! Textos esenciales. (Recopilación y notas de Carmen María Pinilla). Lima, Fondo editorial del Congreso del Perú; pp. 89-102.

ARGUEDAS, José María (2004). "La literatura quechua en el Perú”. En Arguedas, José María, ¿Kachkaniraqmi! ¿Sigo siendo! Textos esenciales. (Recopilación y notas de Carmen María Pinilla). Lima, Fondo editorial del Congreso del Perú; pp. 152-162. ARGUEDAS, José María (2004). "El complejo cultural en el Perú y el primer congreso de peruanistas". En Arguedas, José María ¿Kachkaniraqmi! iSigo siendo! Textos esen- 
ciales. (Recopilación y notas de Carmen María Pinilla). Lima, Fondo editorial del Congreso del Perú; pp.184-192.

ARGUEDAS, José María (2009). "El Perú y las barriadas". En Arguedas, José María, ¿Kachkaniraqmi! ¿Sigo siendo! Textos esenciales. (Recopilación y notas de Carmen María Pinilla). Lima, Fondo editorial del Congreso del Perú; pp. 459-461.

ARGUEDAS, José María (2009). Qepa Wiñaq... Siempre Literatura y antropología. Edición crítica de Dora Sales. Madrid: Iberoamericana-Vervuert.

ARGUEDAS, José María (2009) [1939]. "Entre el kechwa y el castellano, la angustia del mestizo". En Arguedas, José María Qepa Wiñaq... Siempre Literatura y antropología. Edición crítica de Dora Sales. Madrid, Iberoamericana-Vervuert; pp. 141-144.

ARGUEDAS, José María (2009) [1950]. "La novela y el problema de la expresión literaria en el Perú”. En Arguedas, José María, Qepa Wiñaq... Siempre Literatura y antropología. Edición crítica de Dora Sales. Madrid, Iberoamericana-Vervuert; pp. 153-160.

ARGUEDAS, José María (2011). Nosotros los maestros. Selección, estudio preliminar y notas de Wilfredo Kapsoli Escudero. Lima: Derrama Magisterial.

BOURDIEU, Pierre (1985). ¿Qué significa hablar? Madrid: Ediciones Akal.

BOURDIEU, Pierre (2002). "El mercado linguiístico". En Sociología y cultura. Mexico, Grigalbo; pp. 143-158.

CORNEJO Polar, Antonio (1970). "El sentido de la narrativa de Arguedas". Revista Peruana de Cultura $\mathrm{N}^{\circ}$ 13-14. Lima; pp. 17-48.

CORNEJO Polar, Antonio (1995). "Condición migrante e intertextualidad multicultural: El caso de Arguedas". En Revista de crítica literaria latinoamericana. Año XXI, $\mathrm{N}^{\circ} 42$, Lima - Berkeley; pp. 101-109.

DE LA CADENA, Marisol (2004). Indígenas mestizos: raza y cultura en el Cusco. Lima: IEP.

DE LLANO, Aymará (2010). "Lo oculto que se hace presente. Los ríos profundos de José María Arguedas". En Arguedas centenario. Actas del congreso internacional José María Arguedas. Vida y obra. Lima, Academia peruana de la lengua, Editorial San Marcos, UNMSM; pp. 132-142.

ESCOBAR, Alberto (1984). Arguedas o la utopía de la lengua. Lima: Instituto de Estudios Peruanos.

ESCOBAR, Alberto (1989). El imaginario nacional. Moro - Westphalen - Arguedas. Una formación literaria. Lima: Instituto de Estudios Peruanos.

ESPEZÚA SALMÓN, Dorian (2008). “iCultura chicha?”. En Casa de citas. Año 3, № 5, Lima; pp. 34-42.

FORGUES, Roland (1991). "El mito del monolingüismo quechua de Arguedas". En Pérez, Hildebrando y Carlos Garayar (editores). José María Arguedas: vida y obra. Lima, Amaru Editores; pp. 47-58.

FORGUES, Roland (1989). José María Arguedas: Del pensamiento dialéctico al pensamiento trágico. Historia de una Utopía. Lima: Editorial Horizonte.

GONZÁLEZ VIGIL, Ricardo (2002). “Introducción”. En Arguedas, José María. Los ríos profundos. Edición de Ricardo González Vigil. Madrid, Cátedra; pp 9-136.

GRUZINSKI, Serge (2000). El pensamiento mestizo. Barcelona: Paidós.

HERMUTHOVÁ, Jana (2004). "El discurso experimental arguediano". En José María Arguedas en el corazón de Europa. Praga: Universidad Carolina de Praga; pp. 29-75. 
HUAMÁN, Carlos (2004). Pachachaka. Puente sobre el mundo: narrativa, memoria y símbolo en la obra de José María Arguedas. México: El colegio de México / Universidad Nacional Autónoma de México.

LÓPEZ GARCÍA, Ángel (2008). "Clases de escritores bilingüies: a propósito de José María Arguedas”. Dialogía, Año 3, n 3, Ayacucho; pp. 95-107.

MAMANI MACEDO, Mauro (2011). José María Arguedas. Urpi, fieru, quri, sonqoyky. Lima: Petróleos del Perú.

MARCH, Kathlee (1984). "El bilinguí́smo literario y la verosimilitud". En Anales de la literatura hispanoamericana. $\mathrm{N}^{\circ} 13$, Ed. Universidad complutense, Madrid; pp. 195-201.

MELIS, Antonio (2011). José María Arguedas. Poética de un demonio feliz. Lima: Fondo Editorial del Congreso del Perú.

MERINO SOLARI, Renatto (2011). "El mestizaje cultural en los escritos antropológicos de José María Arguedas". En Arguedas centenario. Actas del congreso internacional José María Arguedas. Vida y obra. Lima, Academia peruana de la lengua, Editorial San Marcos, UNMSM; pp.397-409.

OSORIO TEJEDA, Nelson (2011). "José María Arguedas y la construcción del lenguaje de la identidad mestiza”. En Arguedas centenario. Actas del congreso internacional José María Arguedas. Vida y obra. Lima: Academia peruana de la lengua, Editorial San Marcos, UNMSM; pp. 410-417.

ROWE, William (1979). Mito e ideología en la obra de José María Arguedas. Lima: Instituto Nacional de Cultura.

SCHMIDT, Klaus Elmar (2005). "Español quechuizado o los límites de la imaginación occidental". En Pinilla, Carmen María (Editora general). Arguedas y el Perú de hoy. Lima, Sur Casa de Estudios del Socialismo; pp. 139-146.

TARICA, Estelle ( 2006). "El 'decir limpio' de Arguedas: la voz bilingüe, 1940 -1958”. En Ramírez Franco, Sergio (editor). José María Arguedas: hacia una poética migrante. Pittsburgh, Instituto Internacional de Literatura Iberoamericana; pp. 23-38. 